\title{
DAS RESSIGNIFICAÇÕES DO PASSADO: As artes da memória e a escrita da história de Caiana dos Crioulos (Alagoa Grande-PB)
}

\author{
Janailson Macêdo Luiz*
}

RESUMO: O artigo problematiza narrativas constituídas em torno do passado de Caiana dos Crioulos, comunidade remanescente de quilombos situada no brejo paraibano, no município de Alagoa Grande. Em especial, são abordadas memórias de moradores locais sobre a formação da sua comunidade e outros períodos longínquos de sua trajetória enquanto grupo, como as violências do período da escravidão e do pós-abolição, inseridos dentro dos "tempos antigos" relatados pelos "mais velhos". Tais representações sobre o passado da comunidade são cruzadas com aquelas constituídas, sobretudo a partir de meados do século XX por sujeitos da sociedade circundante, tais como jornalistas e políticos, assim como, a partir dos anos noventa, pelos próprios membros do grupo, durante a afirmação de uma identidade quilombola, onde suas identidade e seu passado passaram a ser (res)significados.

PALAVRAS-CHAVE: Quilombolas; Caiana dos Crioulos; Memória; Etnicidade.

\section{The (re)signification of the past: the art of Caiana dos Crioulos historical memory and writing (Grande Alagoa-PB, Brazil)}

ABSTRACT: The article studies the narratives about the past of Caiana dos Crioulos, one of the remaining quilombo communities of the Paraiba State marshes, in the city of Grande Alagoa. Notably, are recorded the memories of local inhabitants regarding the formation of their community and of other remote periods of their trajectory as a group, such as the violence of the "old times" - slavery and post-abolition periods - as told by the "elders." Such representations concerning the past history of this community are cross examined with those primarily from the mid- $20^{\text {th }}$ century, by citizens of the surrounding society such as journalists and politicians, as well as, from the Nineties, by members of this very own group, when the Quilombola identity was being affirmed and their identity and past begun to be (re)signified.

KEYWORDS: Quilombolas; Creoles'Cayan [Caiana dos Crioulos]; Memory; Ethnicity.

\section{De las (res)significaciones del pasado: las artes de la memoria y la escritura de la historia de Caiana dos Crioulos (Alagoa Grande-PB, Brasil)}

RESUMEN: El artículo problematiza narrativas constituidas al rededor del pasado de Caiana dos Crioulos, una comunidad remaneciente de los quilombos ubicada en el zarzal de Paraíba, en el municipio de Alagoa Grande. En especial, se abordan las memorias de los habitantes locales sobre la formación de su comunidad y otros periodos remotos de su trayectoria como grupo, como las violencias del periodo de la esclavitud y post abolición, inseridos adentro de los "tiempos antiguos" relatados por los "más grandes". Tales representaciones sobre el pasado de la comunidad son cruzadas con aquellas constituidas, sobre todo a partir de mediados del siglo XX por sujetos de la sociedad circundante, tales como periodistas y políticos, así como, a partir de los años noventa, por los propios miembros del grupo, durante la afirmación de una identidad quilombola, donde sus identidades y su pasado pasaron a ser (res)significados.

PALABRAS CLAVE: Quilombolas; Caiana dos Crioulos; Memoria; Etnicidad.

\footnotetext{
* Mestre em História pela Universidade Federal de Campina Grande. Atualmente é professor de História na Universidade Federal do Sul e Sudeste do Pará (Campus Marabá) e Doutorando pelo Programa de PósGraduação em História Social da Universidade de São Paulo. Contato: Folha 31, Quadra 7, Lote Especial, s/n, CEP: 68507-590, Nova Marabá, PA, Brasil. E-mail: janailsonmacedo@hotmail.com. ORCID: https://orcid.org/0000-0003-3879-4240.
} 
O tempo presente ${ }^{1}$ não se configura, como nossa acelerada sociedade da informação parece querer nos fazer acreditar, como uma mera tábula rasa, isenta de heranças legadas pelo passado ou de projeções orientadas para o devir; muito menos se direciona a um devir único, universalista e desenraizado quanto a noções de pertencimento tidas por partes dos grupos que compõem uma mesma sociedade, como aquelas relacionadas a etnicidade ${ }^{2}$ e a territorialidade ${ }^{3}$.

Em locais como Caiana dos Crioulos $^{4}$ (Alagoa Grande - PB) ${ }^{5}$, onde as pessoas compartilham uma específica noção de territorialidade e de pertencimento à sua comunidade (categoria êmica), chamam a atenção as heranças materiais e imateriais sob as quais seus moradores estão envoltos. Torna-se relevante, portanto, perceber como essas heranças são apropriadas pelas atuais gerações nesta e em outras comunidades tradicionais ${ }^{6}$, em especial as comunidades quilombolas ${ }^{7}$, a partir das questões próprias do tempo presente e de seu dinamismo.

Figura 1: Localização de Caiana dos Crioulos, Alagoa Grande - PB

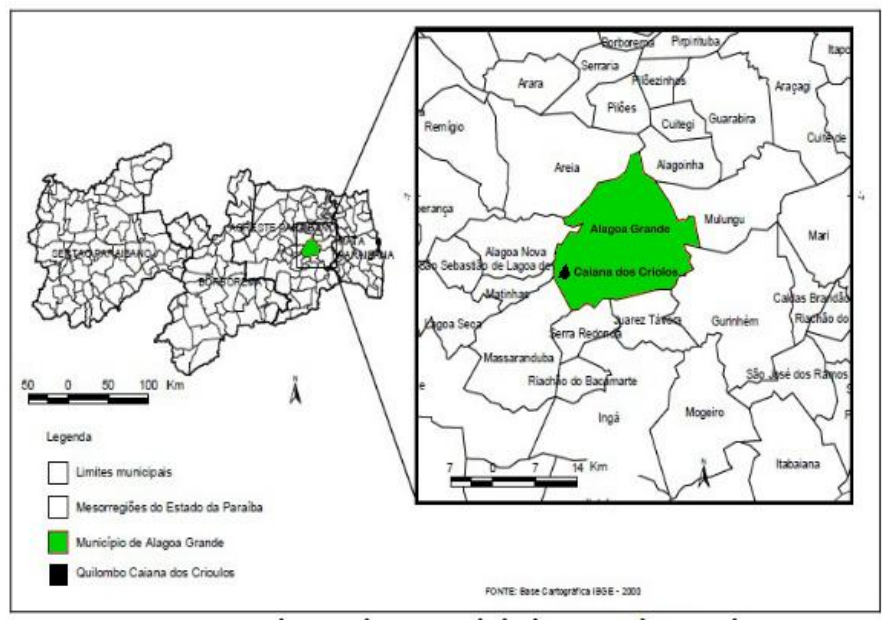

Fonte: Luiz (2013).

Essa relevância se dá não somente devido a um sempre salutar exercício de compreensão do outro, próprio das sociedades e culturas humanas, mas do entendimento também de como construímos nossas formas de transmissão e apropriação das heranças que nos foram legadas, as quais em nossa época recebemos, como nos lembra $\operatorname{Arendt}^{8}$ sem um testamento orientando como devemos ou não proceder quanto aos seus usos em nosso próprio tempo, e sobre o que objetivamos legar para as próximas gerações.

Tal exercício de contato com o outro também é relevante para sermos capazes de compreender elementos que compartilhamos com esses grupos, a exemplo de uma herança 
diaspórica historicamente inerente à nossa sociedade após mais de três séculos de escravidão. Tal legado no Brasil não se restringe aos quilombolas, mas tem nesses grupos, e em suas formas de organização social e cultural, um dos seus principais representantes.

Em tempos como os de hoje, onde as políticas voltadas para os quilombolas encontram-se sob ameaça, e não somente no que se refere ao avanço do latifúndio sobre suas áreas, mas também em virtude da emergência de visões autoritárias que buscam deslegitimar a própria existência desses grupos ${ }^{9}$, torna-se ainda mais importante refletir sobre como atuamos em relação a esse legado, e sobre como, enquanto sociedade, nos relacionamos com grupos que lidam com ele mais diretamente em seu dia-a-dia.

Nas páginas que se seguem apresentarei o resultado de compreensões reunidas durante pesquisa de campo desenvolvida em Caiana dos Crioulos, sobretudo durante o ano de 2012, durante a produção da minha dissertação de mestrado, que se valeram também de fontes bibliográficas, artigos em jornais e periódicos e impressões colhidas em outras atividades de campo desde o ano de 2006, quando iniciei o contato com moradores da comunidade ${ }^{10}$.

Na pesquisa de campo, assim como no desenvolvimento do trabalho como um todo, lancei mão de uma aproximação entre a História e a Antropologia, em especial entre a História Oral, a partir de Alberti ${ }^{11}$, onde a entrevista é vista não apenas como um relato de ação mas também como uma ação, dando-se maior importância para o momento de constituição da narrativa oral; e a pesquisa etnográfica, através da observação participante, baseada não somente no "eu estive lá", mas no entendimento da importância de se conviver com o grupo, para melhor compreensão dos significados que eles atribuem ao seu cotidiano e, no que interessa à pesquisa, aos temas levantados nos problemas que a orientam.

Voltei-me inicialmente para as formas como parte dos moradores da Caiana do presente interpretam suas origens e eventos ocorridos em momentos mais longínquos da trajetória de sua comunidade no decorrer do tempo, apropriando-se do que lhes fora narrado por seus antepassados. Como pude perceber durante a pesquisa, eles buscam interpretar essas narrativas a partir da relação entre o que lhes foi legado e as demandas do contexto atual, marcado pela ampla procura de sua comunidade por parte de agentes externos, em destaque pesquisadores, como eu, após o reconhecimento enquanto remanescente quilombola. $\mathrm{O}$ processo visando tal reconhecimento fora iniciado no fim dos anos 1990, vindo a comunidade a ser certificada em 2005 como remanescente quilombola.

Entre tais apropriações efetivadas em Caiana dos Crioulos, destacam-se as versões sobre as origens da comunidade, bem como os relatos presentes na memória coletiva do grupo 
acerca dos períodos mais longínquos no tempo, como narrativas ligadas ao período da escravidão, ao pós-abolição e mesmo aos grupos indígenas ${ }^{12}$ que segundo os moradores "mais velhos" teriam habitado em outros tempos o espaço atualmente ocupado pela comunidade.

Ao abordar tais relatos sobre as origens não busco uma verdade primeira ou uma essência a ser justificada por essa origem, mas compreender um pouco melhor a história das representações sobre o passado de Caiana dos Crioulos construídas por parte dos próprios moradores da comunidade, muitas vezes em interface e diálogo com os "de fora".

Nos relatos orais, assim como em outras fontes, as representações sobre o passado são construídas a partir do presente, entrando em cena caraterísticas própria da memória, que é sempre dinâmica, como a seletividade, bem pontuada por Halbwachs ${ }^{13}$. Durante as entrevistas, mais do que buscar identificar se as informações apresentadas eram verdadeiras, importava compreender o seu sentido para o(a) narrador(a) e o grupo ao qual ele(a) faz parte.

\section{Memórias da escravidão}

A presença negra no Brejo paraibano decorre, sobretudo, do processo de escravidão vigente nos períodos colonial e imperial. Desse modo, Alagoa Grande e o Brejo paraibano não estiveram dissociados da história da escravidão negra no Brasil, que durou quase quatro séculos.

Essa presença esteve vinculada de modo mais específico à utilização da mão de obra escrava na agricultura, seja por meio da produção de gêneros de subsistência (como milho, feijão e mandioca), seja voltada para as monoculturas do algodão e, principalmente, da canade-açúcar. Também foi importante o cultivo do café, fumo e agave, em especial durante o século XIX. Finalmente, a cana-de-açúcar passou a dominar o cenário agrícola do Brejo, sobretudo na segunda metade do século XIX, dando forte destaque para os engenhos ${ }^{14}$.

Durante a colonização portuguesa no Brasil, o engenho era a unidade básica de produção. Na Paraíba, os senhores de engenho do Brejo, porém, não contavam com o mesmo prestígio dos senhores da região da Zona da Mata, tanto por geralmente se constituírem como pequenos e médios produtores dedicados menos à produção do açúcar e mais à fabricação da rapadura e aguardente, quanto por muitas vezes não se dedicarem exclusivamente à cana-deaçúcar, destinando parte da terra cultivável de suas propriedades para outras culturas.

Apesar disso, os engenhos do Brejo foram importantes para a organização da economia do estado, por estarem no ponto intermediário entre os produtores de açúcar do 
litoral e os pecuaristas do sertão, assim como seriam fundamentais para a constituição das oligarquias locais. Segundo Avelar:

Os lucros dos 'senhores de engenhos' do brejo paraibano com a rapadura, a aguardente e o açúcar, eram inferiores à posição social que ocupavam. Havia mais 'nome', havia, como se diz nos dias de hoje, mais status do que dinheiro. Só com a renda dos engenhos (alguns tinham outras fontes lucrativas, herdadas e/ou adquiridas, atingindo a riqueza) eles viviam mais ou menos equilibrados financeiramente falando (vários enfrentando algumas crises financeiras), mas não eram ricos nem mesmo a nível regional ${ }^{15}$.

Inicialmente, a mão de obra indígena foi utilizada no trabalho com a cana-de-açúcar. No entanto, devido a alguns fatores como a lucratividade possibilitada pelo comércio de africanos e a grande mortandade dos indígenas, esses trabalhadores foram substituídos por negros escravizados. Estima-se que entre os séculos XVI e XIX, mais de doze milhões de africanos foram comercializados através do tráfico atlântico e migraram forçosamente para outros continentes, num processo designado como diáspora africana, e trazidos para a América, com destaque para o que hoje se constitui como o Brasil ${ }^{16}$. Desses, mais de quatro milhões teriam vindo para a América Portuguesa e, posteriormente, para o recém-criado Estado brasileiro. Mas, de onde foram trazidos os africanos que se tornariam escravos na Paraíba? De acordo com Lima, Lima e Rocha:

As pessoas que foram escravizadas na Paraíba, do final do século XVI ao XIX, eram provenientes de diferentes povos africanos, entre os quais se destacaram os bantos, da região da atual Angola, que abrangia três grandes áreas, nas quais se encontravam variados grupos étnicos como os congos, gabãos, cabindas, bacongos, benguelas, ovimbundos, cassanges, angolas, cabundas, rebolos e muitos outros ${ }^{17}$.

Ainda segundo os mesmos autores, a maior parte dos africanos escravizados trazidos para o Agreste paraibano, do qual o Brejo é tido atualmente como uma de suas microrregiões, era de origem banto ${ }^{18}$.

Depois de sua saída dos portos africanos e do processo de travessia do Atlântico nos tumbeiros (navios negreiros), desembarcando no porto do Recife, esses escravos eram enviados para a Goiana, onde eram distribuídos para as regiões do interior, inclusive para o Agreste paraibano ${ }^{19}$.

Em Caiana circulam memórias relacionadas ao período de escravidão no Brejo paraibano. Essas memórias são reproduzidas de forma sub-reptícia e sem uma associação direta, por parte de quem narra, aos seus ancestrais. Quando indagados se a comunidade teria se formado a partir de ex-escravos, os moradores "mais velhos" respondem que seus 
antepassados não lhes relataram nada a respeito. No entanto, mudando-se a categoria, e falando-se em "cativeiro", aparecem algumas narrativas originárias dos "tempos antigos".

Atentei para isso pela primeira vez em 2009, durante uma entrevista realizada com Edite José da Silva (Dona Edite), atualmente com pouco mais de setenta anos. Dona Edite é uma das lideranças da comunidade, e está à frente de um dos grupos de ciranda e coco de roda $^{20}$ de Caiana, além de ser uma das pessoas que guardam a memória do grupo e que mais são requisitadas por agentes "de fora" que procuram a comunidade para a realização de pesquisas. Colaborou em diversos momentos da pesquisa, constituindo-se como aqueles indivíduos chave para a melhor compreensão das concepções e visões de mundo tidas pelo grupo.

Naquele momento, já havia concluído as entrevistas sobre a participação de Dona Edite no grupo de cirandeiras do local, a partir de entrevistas, à época, feitas com base na história oral temática e, portanto, mais limitadas quanto à liberdade narrativa dada aos sujeitos da pesquisa. Após concluir aquelas entrevistas, percebi que novas lacunas se faziam presentes, e resolvi fazer uma entrevista aberta, dando, sem saber, início ao que iria posteriormente desenvolver como recurso metodológico durante o mestrado.

Conversávamos e assistíamos televisão, na sala de sua casa, rodeados por seus filhos, netos, esposo e outros parentes, quando, ao ver uma propaganda de televisão sobre uma novela que tratava do tema da escravidão no Brasil, indaguei-a se os moradores antigos contaram alguma coisa sobre o tempo do "cativeiro", categoria que já havia percebido ser mais apropriada por alguns moradores do local, a exemplo da própria Dona Edite, que me respondeu que:

Eles contava. Porque nesse tempo dos cativeiro, eles não podia usar sapato. Aí, o caçado e eles caçava, era a tal da pragata. Agora, era feita de umas correia de couro, cum... assim, pur debaixo vinha um pedaço de sola, infiava aquelas duas correia na sola, dava um nó em cima. E num era nem todo mundo que pudia usar essas pragata. A roupa, era saco que eles se vistia, cas roupa era de saco. Ou saco, ou um tal de vuco-vuco, ou estopa, era feita a roupa dos hómi, e a roupa das muié, nessa época ${ }^{21}$.

Note-se que fica impreciso se esse tempo do "cativeiro" diz respeito de fato ao processo de escravização ou faz alusão ao período pós-abolição, muitas vezes descrito também pelos "mais velhos" de Caiana como uma época em que as populações pobres da região e da própria comunidade estavam submetidas ao jugo dos "fazendeiros" (coronéis) locais e, por isso, ainda viviam uma situação de "cativeiro". Os relatos de memória coletados 
relacionam tais episódios a uma temporalidade que não coincide com o tempo oficial do calendário, mas com o que fora vivido outrora pelos "mais antigos".

Dois anos depois pude aprofundar, na pesquisa de mestrado, o contato com as narrativas dos moradores, sobretudo os "mais velhos" da comunidade. Como Rios e Mattos ${ }^{22}$, passei a considerar em conjunto os relatos coletados nas entrevistas e nos contatos informais durante a pesquisa de campo, sendo guardadas as especificidades do lugar de fala de cada narrador(a) no interior do grupo. Aquelas autoras chamaram esse conjunto de etnotexto, que em sua pesquisa tratava de narrativas sobre a escravidão no sudeste cafeeiro.

Em ambos os contextos permaneceram memórias subterrâneas, como diria Pollack ${ }^{23}$, a respeito da escravidão e suas consequências, mesmo passados mais de cem anos. $\mathrm{O}$ que mostra não somente a relevância no tocante a manutenção dessas memórias por parte dos grupos, mas também que tais narrativas, ligadas a memórias de violência e dor, ainda trazem experiências que precisam ser rememoradas no tempo presente.

Tais memórias subterrâneas sobre a escravidão não são encontradas apenas em Caiana dos Crioulos. Rios e Matos ${ }^{24}$ problematizaram memórias do tempo do "cativeiro" reunidas em pesquisas junto às algumas comunidades negras no Sudeste cafeeiro. A partir da leitura de $\operatorname{Matos}^{25}$ são encontradas algumas similitudes entre os relatos apresentados em Caiana e no Sudeste do país. Ao tratar das narrativas analisadas na referida pesquisa, Matos aponta que:

\begin{abstract}
Na maioria delas, o trabalho é antes um ponto de continuidade do que de ruptura entre o tempo do cativeiro e o tempo da liberdade. São os direitos e ir e vir, de dispor de seu próprio corpo e de regular autonomamente as relações de família que marcam as descontinuidades a serem ressaltadas entre "Tempo do Cativeiro" e o "Tempo de Liberdade", nas falas baseadas na tradição familiar dos descendentes diretos dos últimos cativos do continente.
\end{abstract}

Dona Edite, na mesma entrevista em 2009, ao ser solicitada por mim a tecer um relato sobre a chamada "pedra da costureira" - pedra "encantada" situada numa comunidade próxima a Caiana, sobre a qual ela havia me falado em um contato informal - apresentou uma narrativa presente em Caiana acerca dos fazendeiros que outrora circundavam a comunidade. Nessa representação ${ }^{26}$, encontram-se não só indícios de práticas típicas do período escravista continuadas no pós-abolição, como também as significações negativas atribuídas pelos moradores de Caiana com relação às mesmas:

(...) Agora, nesse alpendre, tinha um mata-burro, que chama, um mata-burro é essas, essas toice de pau, que faz aquele rolo de pau. Aí, pronto, nesse mata-burro, quando a pessoa num era, quando a pessoa num fazia as coisa certa com ele [o filho de um fazendeiro], ele pegava aquele... Aqueles hómi, aí eles fazia aquelas pessoa correr 
por cima daqueles mata-burro; e naqueles mata-burro, eles, às vezes os pé sacudia, quebrava a perna. Quando quebrava a perna. Ou eles judiava de qualquer maneira. Aí o debaixo do mata-burro, era um buraco só, desse lado aqui era a parede, ali era parede e isso aqui era oco (...) Aí nessas loca de peda, tanto ia hómi como ia muié, aí com os tempo, essa peda se apresentou sendo a Peda da Costureira, que ele diz que mulé custurêra que eles matava, que butava nessa peda, e quando o pessoá passava fora da hora da noite, escutava essa... Essa máquina custurando lá nessa peda. Só se via a máquina tá-tá- tá-tá- tá-tá- tá-tá- tá-tá. Eles ia atrás e num via ninguém. Diz que era... Era osso de gente, era resto de roupa de gente, tudo tinha lá nessa peda, que eles num enterravo! O bicho cumia e ficava lá o resto. E essa peda sempre custurava $^{27}$.

Essa narrativa se relaciona a experiências, como bem apontado por Benjamim ${ }^{28}$, transmitidas de geração e geração, que se por um lado fizeram com que não se esquecesse dos atos e abusos cometidos pelos fazendeiros e seus herdeiros, também mantinham em constante alerta os moradores e moradoras da região. Por isso, naquela época, a pedra "sempre custurava", lembrando a quem dela se aproximasse o tipo de relações instituídas ali pelos arredores.

\section{As artes da memória e as histórias que os mais velhos (não) contaram}

Arruti lançou mão da categoria arte para designar a especialidade exercida pelas pessoas que, no cerne da comunidade remanescente de quilombos do Mocambo-SE, exerciam o papel de rememorar em nome do grupo. Segundo aquele autor:

O Mocambo não dispunha de uma 'memória coletiva', no sentido tradicional em que essa expressão se opõe à memória individual e que supõe a sustentação de uma 'identidade coletiva'. O que ocorreu foi a sua transformação em uma arte ou especialidade dominada por poucas pessoas, com a anuência da coletividade ${ }^{29}$.

Ricoeur e Pollack ${ }^{30}$ demonstraram a necessidade de se considerar, respectivamente, o esquecimento e o silêncio durante o estudo da memória. Silêncio que comunica para o leitor os interditos que perpassam o ato de configuração narrativa, e os limites entre o que é desejável/permitido dizer por parte do sujeito lembrante e o que é preferível manter sob a terra, nos subterrâneos; esquecimento que, se não existisse, transformaria a memória em algo monstruoso, como ocorre com o personagem do conto "Funes: o memorioso", do escritor argentino Jorge Luís Borges, que por ser incapaz de esquecer-se vive apenas para contemplar as suas próprias memórias. ${ }^{31}$

Segundo boa parte dos moradores atuais de Caiana, em especial as pessoas acima de sessenta anos, os seus pais e avós e aqueles que os antecederam, não tinham o costume de repassar suas histórias pessoais, familiares e com relação aos seus antepassados. 
Essa não-transmissão, segundo eles, seria ocasionada pelos seguintes motivos: a) não terem os moradores mais antigos o nível de escolarização e conhecimento suficiente do mundo letrado para compreender que deveriam transmitir determinadas memórias para os mais novos; b) serem seus antepassados pessoas "fechadas" e que não tinham o costume de ficar muito tempo "de conversa" com os outros, principalmente com indivíduos "de fora" ou crianças e jovens da própria comunidade; c) os moradores da comunidade, nessas épocas mais antigas não perguntarem aos seus pais e avós como a comunidade havia se formado, sendo que nem mesmo os atuais "mais velhos" (segundo eles mesmo afirmam) quando vivenciavam sua juventude apresentavam tais questionamentos aos seus ascendentes.

Nesse sentido, os moradores "mais velhos" da atualidade justificam esse nãoperguntar tanto pelo medo que tinham, quando crianças, dos seus pais e outros membros da família, que inviabilizava diálogos desse tipo, quanto por naquele período não haver a necessidade de realizar tais perguntas, devido a história da comunidade não se constituir como elemento a ser então problematizado por "ninguém saber que ia precisar disso depois", como me narrou certa vez Dona Luzia. Segundo ela:

(...) se fosse coisa mermo que os mais véi cunversasse com os mais novo, os mais novo tinha mais história, porque aqui em Caiana tem muita história. Agora, porque o pessoal mais vei num contava, num conversava. Mas aqui tem muita história pra contar! ${ }^{32}$

Com base nas hipóteses mais consistentes ao se observar o surgimento de outras comunidades designadas hoje como remanescentes de quilombos, bem como em hipóteses lançadas pelos próprios moradores do local - melhor abordadas nos próximos itens existiram motivos para que os membros das primeiras gerações que residiram em Caiana tivessem optado por não transmitir às gerações mais novas o que lhes tinha levado a morar ali e como havia se iniciado essa moradia ${ }^{33}$.

A primeira hipótese, externa à comunidade, vincula a origem de Caiana à formação de um quilombo nos moldes da definição vigente na época colonial, onde o mesmo era constituído por negros fugidos do "cativeiro" que em conjunto organizavam formas alternativas de organização social. Seguindo essa versão, não seria de se estranhar que os moradores mais antigos da comunidade almejassem apagar a pecha atribuída até então aos "quilombolas", designação dadas aos agrupamentos que reunissem ao menos cinco negros fugidos, e que fora ressemantizada pelo Estado em 1988, ao criar-se a categoria de "remanescentes dos quilombos" e inseri-la na Constituição Federal ${ }^{34}$. 
Se na atualidade as ações dos quilombolas da época colonial são exaltadas nos meios culturais e glorificadas por alguns segmentos na figura de Zumbi dos Palmares; na época da Colônia e do Império os mesmos carregavam consigo a alcunha de bandidos, saqueadores, assassinos e ladrões ${ }^{35}$. Imagem que, ao se aceitar essa primeira hipótese, poderia ser suficiente para que fosse colocada em funcionamento uma sutil estratégia de esquecimento por parte dos moradores de Caiana, que teriam resolvido silenciar-se sobre o seu passado. Essa hipótese é defendida por Freire, ao afirmar que:

\begin{abstract}
Nem mesmo os mais velhos moradores da Caiana dos Crioulos sabem como lá chegaram os seus primeiros habitantes. Possivelmente, com medo de serem presos e sofrerem as terríveis conseqüências como escravos fugitivos, os seus ancestrais procuraram destruir tudo que fosse indício dessa situação, inclusive não passando aos seus filhos e netos suas origens e como chegaram ao território alagoagrandense $\mathrm{e}^{36}$.
\end{abstract}

A segunda hipótese, também externa, relaciona a origem de Caiana ao fím da escravização na Paraíba e no Brasil, ocorrida no ano de 1888. Em uma sociedade repleta de formas de segregação social e ainda fortemente marcada pelo racismo, não haveria mesmo qualquer vantagem para os sujeitos outrora escravizados vangloriarem-se de sua condição anterior ou mesmo fazer a ela qualquer referência.

Isso não significa que não aconteceram transmissões desse tipo, mas mostra que as mesmas tendiam a ser evitadas, pois se apagando determinados rastros do passado, seriam minimizados - em especial para as gerações mais novas - as imagens negativas que os acompanhavam.

O motivo da exposição dessas duas hipóteses acima, que não necessariamente se excluem entre si, é demonstrar que os moradores mais antigos de Caiana poderiam sim ter possuído motivos para deliberadamente cultivar o silêncio sobre a origem da ocupação daquele espaço. Afinal, isso ajudaria a compreender o fato de, mesmo gerações mais recentes serem descritas como "fechadas" pelos atuais moradores "mais velhos", visto que esse "fechamento" também foi constituído historicamente, mesmo que não seja possível conhecer os motivos que o ocasionaram.

\title{
"Hoje em dia já é liberto"
}

Outro ponto relevante a ser problematizado diz respeito ao grau elevado de desconfiança tida pelos moradores antigos com relação às pessoas “de fora”; desconfiança 
essa que tinha vínculos com sua fama de "fechados", seja para seus filhos, seja para os moradores das comunidades ao redor e, em destaque, os habitantes da área urbana de Alagoa Grande.

Moura e Vicente reproduzem, no trecho exposto abaixo, a representação ainda hoje presente com relação aos moradores de Caiana nos espaços urbanos de Alagoa Grande. Em primeiro lugar, cita as supostas perdas de seus "traços culturais do passado" para em seguida expor a fama de "arredios, silenciosos e desconfiados" que perseguem desde há muito os moradores de Caiana:

\begin{abstract}
De forma controversa, mas indiscutível etnia, os negros da Caiana vêm perdendo, ao longo dos anos, quase todos os traços culturais do passado, a partir da invasão das antenas de tevê e dos fios telefônicos. Mas até duas, três décadas atrás, seus habitantes se vestiam com roupas coloridas, predominando o vermelho, o rosachoque e o amarelo-ouro. Lenços e turbantes brancos completavam a indumentária africana típica. Arredios, silenciosos e desconfiados até hoje, os crioulos tiveram na música seu principal e elo de integração com os habitantes da cidade ${ }^{37}$.
\end{abstract}

É importante observar se determinados traços do passado são perdidos pela comunidade; a passagem do tempo é também responsável pela definição de novas características, que não são criadas ao acaso, pois as ações presentes se relacionam com aquilo que foi herdado pelo passado sem que isso signifique o abandono de características étnicas próprias, regidas pela dinâmica das transformações culturais e pela negociação das fronteiras étnicas.

Com base em afirmativas como essas a respeito da fama de fechados dos antigos moradores, encontradas também por mim em outras fontes e durante a pesquisa de campo em Alagoa Grande, decidi questionar alguns dos moradores do local no intuito de compreender suas significações acerca dessa fama de "arredios" dos seus antepassados.

Dona Edite, por exemplo, ao ser questionada se era verídica a fama de arredios dos antigos moradores e se as pessoas que chegavam "de fora" era bem recebidas, afirmou:

Era não. Num vou dizer que era, que num era não. Purque antigamente quando vinha - mai num era cum preconceito era cum medo - Quando vinha um pessoa assim de fora pa qui pa Caiana o povo tinha medo demai, home! Imaginava que era um bicho de sete cabeça. Ninguém queria saber! Quando cumeçou a aparecer essas vacina que dá em criança, Ave Maria, que chegou gente aqui pro mode dá essas vacina nas criança, os pessoá num aceitaro não. Uns aceitava, e quando uns aceitava dez, doze num queria. Foi um maior sufoco pro mode se aceitar essas vacina atravei de muita cunversa, mai hoje em dia já é liberto. Chegá uma pessoa assim que nem tu chegou agora na minha casa? Pro mode faz que nem diz o ditado; Chegava aqui cunhecia meu pai, cunhecia minha mãe. Aí pronto mai nói tava tudo lá pá dento. Se pai dissesse: 'vá olhar!', a gente vinha e se pai num dissesse 'num vai olhar' de lá de dento ninguém num saia não. Saia ou pai ou mãe atendia aquela pessoa aqui fora e a 
gente lá dento ficava pa fora e ninguém saia não. Mai hoje em dia quando uma pessoa diz 'ô de casa' quem primeiro corre é a criançada. Antigamente num tinha isso $^{38}$.

Em outro depoimento, ela também utilizou a expressão "liberto", dessa vez ao tratar das mudanças entre o acesso que a sua geração e as anteriores tiveram à escolarização e o acesso disponibilizado aos jovens de hoje:

(...) e hoje em dia os minino são liberto, puque a gente tinha que trabaiá qui era o meu pai trabaiava pros alugado do povo, e a gente tinha que trabaiá em casa pu mode sustentá fai qui nem di o ditado pa ter o mantimento da família em casa ${ }^{39}$.

Para Mané Guilherme ${ }^{40}$, que em 2012 tinha 93 anos de idade, a Caiana do fim de sua infância e juventude também se distinguia bastante da Caiana de "hoje em dia":

Aqui num vinha ninguém de fora não. E era trancado assim, que nem um... um jacaré. Era um... era um... era um mogeu [museu] aqui antigamente. O senhor batia aqui nesse mei de mundo por todo canto aqui, onde o senhor andasse, como que nem a gente assim. Chegava numa casa dos moreno assim. Eles tava na porta assim. $\mathrm{O}$ senhor vinha pelo caminho... quando o senhor desse a volta, naquele pra entrar... eles batia as porta... Té hoje!

O senhor podia falar, morrer de falar, e falar... o diabo... [Eles] Falava nada hôme. Hum?

Hoje em dia não! Hoje cê chega: "Oie!" [e eles respondem] "Humhum!", "humhum!". Que eles tem uns: "humhum!", "humhum!". "Hum!, cumprade", "É mesmo, cumpadre!", "humhum". Pronto! E hoje tão se saindo...

A Caiana do passado, nesse caso referente, por dedução a partir de sua idade e por outros relatos, aos anos 1920-40, é descrita por ele como um "mogeu" (museu), devido ao seu isolamento com relação ao "resto do mundo". Também fica implícita nessa representação a convivência de temporalidades distintas, sendo uma delas a de quem vinha "de fora", mais afeita aos hábitos, costumes e conhecimentos relacionados à modernidade; e a outra aos que viviam do lado "de dentro" da comunidade, que guardavam comportamentos e, como é descrito no trecho em destaque, temores próprios de épocas mais afastadas no tempo, que continuavam presentes no período pós-abolição, mas que nos dias atuais, de acordo com o já falecido Mané Guilherme, não seriam mais encontrados.

\section{Representações sobre os as origens}

Apesar de afirmarem que seus antepassados não lhes contaram como se deu a sua origem da comunidade, os moradores de Caiana entrevistados vêm na atualidade se 
questionando sobre essas origens e têm se apropriado de algumas versões vindas "de fora", sempre registrando que não lhes foram transmitidas pelos "mais velhos".

Dentre essas versões, a mais presente é a que relaciona a origem de Caiana dos Crioulos a uma rebelião escrava que teria se iniciado no interior de um navio negreiro recém desembarcado em algum ponto do litoral da Paraíba ou de Pernambuco, durante o período Colonial. De acordo com Dona Edite, essa história teria chegado à Caiana:

Também já por cunversa dos outo. Que a gente, porque eu também num sei, nem meu pai nunca disse como foi que eles, que esse povo chegaro aqui. Ma o pessoal diz que viero num navi da África, e esse navi quando chegaro ali na Paraíba ou foi no Recife, num sei onde foi. Ali esse navi desimbarcô esse povo, e povo que já viero da África, viero currido. Aí saíro caçando lugar mais escondido pra se escondê, mode os patrão... por certo os patrão num... na procura deles ${ }^{41}$.

Antes de iniciar a narrativa Dona Edite faz questão de deixar claro que havia tomado conhecimento da mesma por "cunversa dos outo", que ela não sabia se a mesma era verídica, nem seu pai havia lhe narrado como a origem da comunidade teria de fato ocorrido. Algo semelhante ocorreu em diversos outros depoimentos, nos quais os colaboradores adotaram o mesmo posicionamento com relação a essa narrativa. Um deles, Seu Manel (Manoel Firmino Luiz, a época com quase setenta anos), chegou mesmo a afirmar que "aquela pessoa que falá que os mai véi contaro como vieram pará aqui tá mentindo, e eu digo na cara dela, que ela tá mentido, purque os mai véi num contaram como os primero chegaram aqui não"42.

Paiva e Souza, ao produzir em 1999 seu relatório de identificação de Caiana dos Crioulos, a mando da Fundação Cultural Palmares, foram claros ao expor que:

Nos depoimentos coletados na região e nas explicações que hoje são dadas por alguns dos integrantes de Caiana, aqueles mais engajados no processo de reconhecimento da identidade quilombola, a origem de Caiana teria algumas explicações associadas a hipóteses também apresentadas pela sociedade envolvente e que a comunidade tem se apropriado na intenção de reconstruir sua história ${ }^{43}$.

Em minha própria pesquisa pude presenciar, por meio de falas como a produzida por seu Manel, as tensões existentes atualmente em Caiana com relação às narrativas que versam sobre a formação da comunidade.

Observei pelo menos três posturas com relação a essas narrativas no cerne de Caiana: a) algumas pessoas as utilizam como elemento explicativo, mas deixando claro que não foram narrativas transmitidas pelos "mais velhos" e dando a elas um sentido de hipótese, como foi o caso do trecho apresentado acima por Dona Edite; b) negar sua veracidade, por não ter sido algo que os "mais velhos" tenham contato e, portanto, não merecer crédito, como 
exemplificado pela fala de Seu Manel; c) transmiti-la, mesmo sem necessariamente afirmar que os "mais velhos" as teriam repassado para as gerações atuais ou sem atribuir um sentido de verdade a ela.

Em 1949, o alagoa-grandense Ivaldo Falconi assinava o artigo "Um quilombo esquecido", onde afirmava que:

\begin{abstract}
Nenhum dos negros que interrogamos, mesmo os mais velhos, têm a menor idéia a respeito da origem dos primeiros habitantes da região a dos quais são eles descendentes. Nenhum, igualmente sabe dar qualquer informação sobre a vida e sobre os fatos mais recentes da história daquela comunidade. José Punaro, negro de quase setenta anos e que é o chefe do agrupamento, apenas nos mostrou as casas em que moraram seu pai e seu avô. Não resta dúvida pois, de que a comunidade rural dos negros de Caiana tem mais de cem anos e de que muito antes da Abolição ela já existia. Tudo, por isso, leva a crer que se trata dos restos de um quilombo, formado muito antes da Abolição, por escravos fugidos dos engenhos de Campina Grande, Alagôa Nova, Areia e Alagôa Grande. Vivendo em uma serra de acesso difícil e acidentado e ao tempo coberta de densa vegetação, longe das estradas, permaneceram ali ignorados ${ }^{44}$.
\end{abstract}

Evidentemente, alguns dos moradores interpelados por Falconi e seus companheiros, inclusive o próprio José Punaro, poderiam conhecer a história da formação de Caiana. Contudo, a desconfiança e uma possível prática de silenciamento podem ter entrado em cena durante aquele contato, tornando impossível ao autor do artigo desvendar a origem da comunidade.

Falconi, no entanto, faz revelações interessantes, ao afirmar ter visto as ruínas das casas onde viveram o pai e o avô de Seu Zé Punaro, o que pode de fato significar que a comunidade exista desde pelo menos a metade do século XIX.

Se o velho líder de uma das bandinhas de Caiana possuía mesmo cerca de setenta anos no período da visita de Falconi, então teria ele nascido por volta de 1879. Do mesmo modo, se somarmos ao menos vinte anos para cada geração que o antecedeu, seu pai teria nascido em torno de 1859/1860. Quanto ao seu avô, que nessa hipótese poderia ter nascido por volta de 1839/1849, restaria saber se já teria vindo de outro local ou se era originário dali mesmo.

Entre os parentes de Zé Punaro a que tive contato, sobretudo seu neto Zé Duca - que em 2012 tinha sessenta e seis anos de idade, praticamente a mesma idade do avô na época da visita de Falconi - estes relataram já não guardar qualquer memória sobre gerações anteriores a do líder da bandinha, apesar de mostrarem sempre lembranças do mesmo relativas à sua participação no "pífano" ou em episódios do cotidiano familiar.

No mesmo ano da visita e publicação do artigo de Falconi (1949), Caiana estava em debate nos círculos políticos e intelectuais de Alagoa Grande. Naquele ano, o político e 
escritor Celso Mariz (1885-1982) proferiu uma conferência no teatro Santa Ignêz onde registrou que:

\begin{abstract}
Não pude ir visitar os pretos de Caiana, grupo que oferece uma nuance tão pitoresca à paisagem etnológica de Alagoa Grande. Instalados em suas terras próprias, seus papéis, suas escrituras ou o uso capião de suas posses esclareceriam talvez a sua origem ou a data de sua emigração para o sítio deste município.

Em 1701 perseguiu-se no lugar Cumbe, mais ou menos nestas zonas, um terrível quilombo de pretos que, se dizia, eram fugitivos dos Palmares. Mas este quilombo é remoto demais e deu-se como destruído por forças regulares e de senhores locais. Não pode ser a origem da concentração atual. Propondo a supor que os pretos de Caiana se fixaram naquele trecho de serra quando a campanha abolicionista de Areia, que se redimiu antes da alvorada de 13 de maio, facilitou a fuga e a libertação espontânea de muitos escravos ${ }^{45}$.
\end{abstract}

Esse trecho mostra como parte da sociedade alagoa-grandense e paraibana daquele período, da qual também era oriundo Ivaldo Falconi, Stuckert e Siqueira, estava alimentando certa curiosidade sobre Caiana, sobretudo pelo destaque que uma de suas primeiras bandinhas de pífano começava a adquirir no local.

Anos depois da visita de Falconi, Stuckert e Siqueira, a origem de Caiana voltaria a ser questionada por agentes "de fora". Era o ano de 1983 e a comunidade recebia a visita da professora do curso de Ciências Sociais da Universidade Federal da Paraíba, Josefa Salete B. Cavalcanti e um grupo de estudantes daquele curso. Em matéria publicada por eles no Jornal da Paraíba, foram apresentadas pela equipe as seguintes palavras sobre a origem de Caiana:

\footnotetext{
Quanto à origem do grupo nada se pode coletar. Observa-se que os antecedentes não são conhecidos com precisão, seja em se tratando de gente com quem diretamente tiveram contato (os avós) seja os que desconhecem por tradição oral. Para além dos tempos vividos pelo grupo, as noções se tornam ainda mais vagas ('faz muito tempo'; 'é coisa muito velha'). O princípio e o contorno da parentela se torna impreciso $^{46}$.
}

Certamente melhor abalizada metodologicamente do que Falconi, Cavalcanti reforça o que já havia sido dito por ele e destaca que não foi possível encontrar entre os moradores de Caiana uma explicação de como ou quando a comunidade havia se originado, algo que difere da versão apresentada em 1999 por Paiva e Souza ${ }^{47}$, que apontaram que naquele momento o grupo estava se apropriando de versões vindas "de fora" durante o processo de afirmação da identidade quilombola. Momento em que era necessário fazer a interface entre aquilo que havia sido transmitido tradicionalmente pelos seus antepassados, e o reconhecimento, político, de seu lugar como pertencente a uma coletividade com ancestralidade negra e que 
participara de um processo de resistência a opressões históricas, segundo a definição dada pelo Estado aos remanescentes de quilombos.

\section{"A dente de cachorro"}

Para finalizar o artigo, apresento algumas narrativas transmitidas pelos ancestrais dos atuais moradores de Caiana sobre os "tempos antigos", especificamente que dizem respeito aos indígenas (provavelmente, do grupo Kariri) que habitavam o espaço da comunidade antes da formação de Caiana.

Adquire destaque, primeiramente, o fato de existirem memórias e relatos diversos na comunidade relacionados a esses indígenas, mesmo que não sejam descritas suas características nem a qual grupo étnico pertenciam. As pesquisas sobre a região apontam os Kariri e os Tarairiú como habitantes das proximidades da Lagoa e serra do Paó até o século XVIII.

A presença indígena no espaço onde atualmente Caiana está localizada é sinalizada pelos "mais velhos" a partir de alguns fatores: a) existirem torrões de barro no solo da comunidade que são relacionados aos resquícios das habitações dos indígenas; b) alguns moradores mais velhos da comunidade terem tido como mães ou avós mulheres indígenas "pegas a dente de cachorro"; c) os moradores de Caiana do Agreste, comunidade vizinha, cuja origem é compartilhada, terem características fenotípicas vistas pelos moradores de Caiana dos Crioulos e por eles mesmos como próximas das características indígenas, o que teria ocorrido a partir de uma origem indígena daquela comunidade.

Segundo os atuais moradores, os "mais antigos" lhes ensinaram que aquelas bolotas de barro maciço e "cozido" encontradas pela região, sobretudo no momento de capinar o mato ou preparar o solo para o cultivo, eram os "torrões dos caboclos brabos". Note-se que o conceito reproduz estereótipos tidos à época sobre os grupos indígenas, especialmente os não aldeados, associados a uma concepção de selvageria, dados os constantes conflitos com os quais acabaram se envolvendo, geralmente em defesa dos seus territórios.

Segundo os moradores de Caiana, esses torrões eram muito comuns no passado, sendo encontrados inclusive em dimensões maiores que nos dias atuais. De acordo com Dona Edite: "quando a gente quebra esse torrão, chega ele é de coração dento, azul, de tão cuzinhado. E a terra num molha ele de jeito nenhum" 48 . 
Nas significações dadas pelos moradores de Caiana, a partir do que seus ancestrais lhes disseram esses torrões são associados às formas como os indígenas que viviam na região construíam suas casas. Ainda de acordo com Dona Edite:

Essas casa deles era feita cum... porque os... as... as pessoa pega, faquentado, faz os tijolo pra fazê as casa, e eles cuzinhava era o barro, lá aqueles torrão, aquele bolo de barro, fazia, aí fazia aquelas casa. Por aqui mermo na minha redondeza ainda existe esse tipo... esse torrão ${ }^{49}$.

Com relação aos indígenas, são contadas ainda outras histórias, como as narrativas relacionadas a mulheres indígenas (sendo uma delas ancestral, possivelmente a mãe ou avó, de um dos antigos mestres-cirandeiros da comunidade, João Maria, falecido no final dos anos 1990) que teriam "sido pegas a dente de cachorro" por antigos moradores homens da comunidade, ou seja, capturadas e trazidas à força para a comunidade. De acordo com Dona Edite $^{50}$ :

\begin{abstract}
Ah, essas história de 'a dente de cachorro' já foi depois deles aqui [os primeiros habitantes]. Aí, por aqui, faz que nem diz o ditado, de antigamente, era tudo mata, aquelas mata virge. Aí, pronto. Aí ixistia essa... Esse... esses índio, que tinha essa história desses índio, desses caboclo brabo. Aí daqui teve gente que pegou - que é caçando assim pelos mato, aí os cachorro via aquelas pessoa e pegava. Aí no que pegava aquelas pessoa, aí no que aquelas pessoa tava pegado, os dono pegava e trazia pra cá. Aí é onde é a história que era pegado a dente de cachorro. Porque os caboclo, esses índio são brabo, ninguém num pegava eles com uma risada, nem cum duas. Aí pegava a dente de cachorro. Aí tem gente aqui que é descendente de índio. $\mathrm{O}$ que acontecia era assim que eles era pegado a dente de cachorro, os que dava pa pegar, os que num dava pa pegar eles sumia. Num era que nem hoje não, que tem uma Oldeia [Aldeia], só dos índio. Eu acho que era assim que o pessoal dizia, né? Que num era, num era seguindo quem vivesse lá, quem eles pegava, pegava, quem eles num pegava iam simbora.
\end{abstract}

Foram diversas as relações estabelecidas de contato entre grupos negros e indígenas nos mais diversos momentos da história do Brasil. Aproximações e distanciamentos, conflitos e negociações, guerras e construções de laços sociais e afetivos. Gomes, ao tratar dos contatos entre quilombolas e indígenas Assurini na região do baixo Tocantins no século XIX pontua que no povoado de Porto Alegre:

Segundo os moradores "mais antigos" este povoado existe há mais de 160 anos e teria surgido com os remanescentes de cabanos refugiados. Após a Cabanagem, em 1838, alguns mestiços, tapuios e escravos fugidos ali se estabeleceram. Como eram na maioria homens acabaram "roubando" mulheres indígenas Assurini de aldeias próximas $^{51}$.

Terá sido essa a mesma motivação dos homens de Caiana? Quais as retaliações dos grupos indígenas após terem suas mulheres "roubadas"? Esse roubo tinha relação com 
agressões anteriores entre os grupos? São perguntas que não temos como responder até o momento, mas que apontam sobre pontos amplamente relevantes das relações sociais e culturais tecidas nos contatos entre negros, indígenas e os colonizadores. Como aponta o próprio Gomes, ocorreram articulações entre alguns grupos indígenas e os colonizadores, objetivando o apoio para a destruição de quilombos no baixo Tocantins, o que provocou o acirramento nos conflitos entre alguns grupos negros e indígenas, como o dos citados Assurini. Conflitos esses que se fizeram presentes, em alguns casos, mesmo até os anos iniciais do século XX.

A simples denominação "caboclos brabos", apropriada em Caiana para descrever os responsáveis pela existência dos torrões, mas também as características dos grupos que viviam nas matas e que não se deixavam aprisionar com facilidade, traz indícios de tensões envolvendo a presença indígena naquele local.

Além disso, a narrativa de Dona Edite e os outros indícios já citados demonstram como os antigos moradores de Caiana, apesar de não terem transmitido de modo direto para as gerações atuais como se deu a origem da comunidade, repassaram narrativas que possivelmente servem como resquícios do cotidiano dos primeiros momentos da mesma, inclusive aqueles já perdidos pelo tempo, como uma habitação indígena que teria sobrevivido próxima à comunidade e sido avistada por alguns dos pais dos atuais "mais velhos", mas que hoje não se encontra mais de pé.

\section{Considerações finais}

Vimos algumas narrativas dos moradores de Caiana com relação aos primeiros momentos de formação da sua comunidade, aos grupos indígenas que teria lhes antecedido naquele espaço, aos tempos do "cativeiro" e a época em que os antigos moradores ainda não eram "libertos", por ainda nutrirem grande desconfiança e medo em relação aos "de fora".

Se as memórias transmitidas pelos seus antepassados não nos possibilitam precisar ao certo as datas e os detalhamentos sobre a origem do grupo, não deixam por isso de se constituir como um riquíssimo material para a compreensão não somente da presença negra no Brejo paraibano, mas de como os moradores de comunidades quilombolas como Caiana vêm ressignificando o seu próprio passado, a partir das demandas do tempo presente e do que lhes fora legado pelos seus antepassados.

Essas narrativas são, além disso, fundamentais para a escrita da história dessa comunidade, assim como ocorre com as outras comunidades tradicionais, onde não se devem 
ser subestimadas a importância e a riqueza de conhecimentos transmitidos pelos "antigos". Conhecimentos que se versam sobre as plantas medicinais e outros saberes tradicionais, também remetem a formas próprias de lidar com a temporalidade.

Se os "mais velhos" de Caiana não legaram diversas narrativas que poderiam ajudar as gerações atuais a representar com mais precisão a sua história, não deixaram por isso de lhes transmitir memórias (assim como silêncios e esquecimentos) acerca dos primeiros momentos de formação da sua comunidade. Como já dito, tais memórias vêm sendo apropriadas pelo grupo no momento atual, em que a comunidade consolida a sua afirmação enquanto remanescente quilombola, passando a ter maior visibilidade e acesso a determinadas políticas públicas; políticas estas historicamente negadas a seus antepassados, que, mesmo apesar disso, não deixaram de se constituir como sujeitos de seus próprios tempos.

Tais memórias, repassadas através da oralidade, trazem ao tempo presente não só o conteúdo em si das narrativas, mas também experiências e visões de mundo constituídas pelos "mais velhos" e repassadas às gerações atuais. Tais narrativas e experiências são vistas, portanto, pelo próprio grupo, como fatores de diferenciação; que ao olhar acadêmico se configuram como marcas de sua etnicidade.

Esses elementos de diferenciação registram a presença de um próprio, de um lugar, a partir do qual eles interagem como elementos de uma história sempre dinâmica, e que em momento algum fora constituída de modo isolado da relação de outros grupos étnicos.

Em outras palavras, não somente um lugar, mas um lugar de memória ${ }^{52}$, que embora coincida com o espaço da sua comunidade, remete igualmente ao intangível, com o que fora herdado dos "tempos antigos", e vincula-se a sua própria cultura.

Suas fronteiras étnicas foram e são constituídas em diálogo e interação, ainda que através de situações em grande medida conflitivas, com os "outros", e orientam o grupo a inserir no presente, suas próprias expectativas em relação ao devir, e ao que deve ser mantido para as próximas gerações.

\section{Notas}

\footnotetext{
${ }^{1}$ Nos últimos anos têm sido profícuas as pesquisas no campo da História que buscam problematizar temas vinculados à chamada história do tempo presente, onde uma das dimensões em destaque, como a apresentada neste artigo, é justamente a presença do passado (ou de vários passados distintos) no presente e as formas como os sujeitos e grupos se apropriam do seu próprio passado e o relacionam aos dinamismos e escolhas do tempo presente e às expectativas constituídas em relação ao futuro. Como pontua Chartier (1996, p. 216): "me parece que essa história inventou um grande tema, agora compartilhado por todos os historiadores, seja qual for o
} 
período de sua predileção: o estudo da presença incorporada do passado no presente das sociedades e, logo na configuração social de classes, dos grupos e das comunidades que as constituem".

${ }^{2}$ Para Barth $(2000 ; 2003)$ os grupos étnicos marcam suas fronteiras em relação aos outros a partir da apropriação de determinados elementos, os chamados fatores diacríticos, que os diferenciam ou aproximam em relação aos outros. Longe de serem um elemento natural ou determinadas a priori pela história, cultura ou outros fatores, as fronteiras étnicas são negociadas em relação aos outros.

${ }^{3}$ De acordo com Anjos (2009, p. 8): "No conceito de território estão agregados os sentimentos de apropriação de uma porção de espaço, assim como, quanto ao seu limite, a sua fronteira. Como o espaço pode ter significação individual ou de um grupo e, portanto, distintas interpretações, a noção de territorialidade é muito importante nesse processo. Dessa maneira, o limite do território não é necessariamente, sempre físico, mas pode se estender até onde a comunidade reconhece a sua influência, o seu exercício de poder. Outro componente relevante é que o estabelecimento e a manutenção do território exigem domínio, controle, regras e normas, gestão da porção do espaço apropriado". Para uma discussão sobre a territorialidade em Caiana dos Crioulos, ver Santana (2011).

${ }^{4}$ A comunidade fica localizada a cerca de $12 \mathrm{~km}$ da zona urbana, a quem é ligada por uma estrada de terra. No período em que fiz pesquisas no local, sobretudo entre os anos de 2008 e 2013, a comunidade possuía cerca de 500 habitantes.

${ }^{5}$ Alagoa Grande está localizada a 103 km de João Pessoa (acesso pela BR 101), capital do estado da Paraíba. De acordo com o Censo 2010 do IGBE, sua população é de 28.479 habitantes. Sua área territorial abrange cerca de $320,563 \mathrm{~km}^{2}$ e seu bioma é a caatinga. Possui densidade demográfica de $88,84 \mathrm{hab} . / \mathrm{km}^{2}$. A maior parte de seu Produto Interno Bruto (PIB) está vinculada ao setor de serviços, sendo seguido pela indústria e pela agricultura (IBGE CIDADES@, 2013).

${ }^{6}$ Indígenas, quilombolas, ribeirinhos, fundos de pasto, faxinalenses, entre outros.

7 Segundo a Fundação Cultural Palmares (FCP), entidade ligada ao Ministério da Cultura: "consideram-se remanescentes das comunidades dos quilombos os grupos étnicos raciais, segundo critérios de auto-atribuição [sic], com trajetória histórica própria, dotados de relações territoriais específicas, com presunção de ancestralidade negra relacionada com formas de resistência à opressão histórica sofrida" (BRASIL, 2008a).

${ }^{8}$ Arendt (2008) reflete sobre o processo de ruptura com a transmissão da tradição no cerne da modernidade.

${ }^{9}$ Em 2017 ocorreu mais um caso sistemático a esse respeito. Um deputado federal, Jair Bolsonaro, cotado para a candidatura à presidência em 2018, fora condenado por uma juíza federal a pagar indenização por afirmar que os quilombolas não serviriam sequer para procriar. Essa fala não se encontra isolada de um projeto que objetiva deslegitimar o direito, constitucional, dos quilombolas à propriedade das terras por eles tradicionalmente ocupadas.

${ }^{10}$ Meus primeiros contatos com os moradores do local se deram em 2006, a partir de atividades do Núcleo de Estudos Afro-Brasileira e Indígenas (NEAB-Í) da Universidade Estadual da Paraíba. Entre 2008 e 2010 realizei pesquisas de iniciação científica e a produção de uma monografia tendo como objeto os grupos de cirandeiras e as cantigas e festas do local.

${ }^{11}$ Sobre a História oral, ver Alberti (2005). Foram entrevistados mais de vinte moradores da comunidade. Quanto à observação participante, foram apropriadas compreensões de Foote-Whyte (1980), entre outros autores, para quem um pesquisador externo ao adentrar o locus da pesquisa de campo deve ficar atento a todos os momentos vivenciados e campo e comportar-se tal qual uma criança (SEEGER, 1980), buscando conhecer os significados no mundo ao qual está se inserindo.

${ }^{12}$ Possivelmente, tratam-se dos indígenas Kariri (Cariris), como apontam publicações sobre os grupos indígenas que habitavam atual agreste da Capitania da Parahyba, durante o período colonial. Como pontua Apolinário (2013, p. 1-2): "Os indígenas Kariri apresentavam-se dispersos em todo o território paraibano (...) As informações contidas no Mapa etnohistórico de Curt Nimuendaju (2002), principalmente as que revelam os diferentes etnônimos encontrados no sertão nordestino, de leste a oeste, se observa a presença dos índios Kariri em vários locais do interior paraibano, como no Agreste, Borborema e no atual Sertão. No mapa, ele coloca este povo como uma família linguística, procurando demonstrar sua distribuição geográfica, assim como faz com as outras famílias e línguas isoladas. Esse mapa, além de distinguir as sociedades indígenas segundo a classificação lingüística, as situa em mais de um local, conforme seu deslocamento ao longo do tempo, anotando sob seu nome, o ano em que ali se encontrava".

${ }^{13}$ Halbwachs, 2006.

${ }^{14}$ Lima, Lima e Rocha (2007).

15 1996, p. 15.

${ }^{16}$ Ferreira (2018).

17 2007, p. 38.

${ }^{18}$ Entende-se por banto "Cada um dos membros da grande família etnolinguística à qual pertenciam, entre outros, os escravos no Brasil chamados angolas, congos, cabindas, benguelas, moçambiques etc. e que engloba 
inúmeros idiomas falados, hoje, na África Central, Centro-Ocicental, Austral e parte da África oriental.” (LOPES, 2012, p. 45).

${ }^{19}$ Lima, Lima e Rocha (2007).

${ }^{20}$ A ciranda, definida por alguns autores como Ciranda de Adultos (PIMENTEL, 2005) e o coco de roda são danças de roda outrora bastante presentes no litoral e demais regiões vinculadas à produção da cana-de-açúcar, entre Pernambuco e Paraíba, a exemplo de Alagoa Grande. Suas origens são associadas ao período da escravidão. Em Caiana dos Crioulos são brincadas desde tempos imemoriais, a partir de instrumentos como a zabumba, o triângulo e o ganzá. Ver Luiz (2010).

${ }^{21}$ As entrevistas estão sendo apresentadas de forma ipisis litteris.

${ }^{22}$ Rio e Mattos (2005) lançam mão do conceito de etnotexto para tratar do conjunto das entrevistas analisadas sobre a memória da escravidão no sudeste cafeeiro.

${ }^{23}$ Pollack (1989).

${ }^{24}$ Rios e Matos (2005).

${ }^{25}$ Matos (2005, p. 50).

${ }^{26}$ Chartier, 1990.

${ }^{27}$ Dona Edite, 2009.

${ }^{28}$ Benjamim, 1985.

${ }^{29}$ Arruti, 2006, p. 219.

${ }^{30}$ Ricoeur (2007) e Pollack (1989).

${ }^{31}$ Esse trecho do conto registra bem a patologia "memoriosa" de Funes, que saturado de memórias, não consegue, na visão do narrador, ao menos refletir sobre elas ou sobre o seu presente: "Tinha aprendido sem esforço o inglês, o francês, o português, o latim. Suspeito, contudo, que não fosse muito capaz de pensar. Pensar é esquecer diferenças, é generalizar, abstrair. No mundo entulhado de Funes não havia senão detalhes, quase imediatos." (BORGES, 2007, p. 108).

${ }^{32}$ Luzia, 2012.

${ }^{33}$ Não constituiu o propósito do meu trabalho, por questão de delimitação de objeto, a busca por fontes que atestassem como os ancestrais dos primeiros moradores passaram a ocupar o espaço onde a comunidade é hoje localizada.

${ }^{34}$ Sobre a ressemantização da categoria quilombo, ver Arruti (2006).

${ }^{35}$ No período colonial teria existido em algum ponto do Brejo paraibano um quilombo chamado de Cumbe, cujos integrantes, segundo Galiza (2017), citando Irineu Pinto e Irineu Joffily, atemorizavam os habitantes das localidades, configurando-se como um temor para os senhores de escravos. Evidentemente, numa sociedade baseada no escravismo, grupos que apresentassem resistência e estimulassem a fuga de mais escravos não passavam a serem bem-vistos. Para uma abordagem clássica sobre o tema, ver Moura (1987); e, para estudos a partir da nova historiografia da escravidão, ver Reis e Gomes (1996).

${ }_{36} 1996$, p. 103.

${ }^{37}$ 2001, p. 30, grifo nosso.

${ }^{38}$ Dona Edite, 2009, grifo nosso.

${ }^{39}$ Dona Edite, 2009.

${ }^{40}$ Mané Guilherme, 2012.

${ }^{41}$ Dona Edite, 2009.

${ }^{42}$ Manel, 2012.

${ }^{43}$ Paiva e Souza, 1999, p. 5.

${ }^{44}$ FALCONI, 1949, s/p.

${ }^{45}$ MARIZ apud AVELAR, 1996, p. 104.

${ }^{46}$ Cavalcanti, 1983, p. 4.

${ }^{47}$ A elaboração de relatório antropológico de identificação é um dos primeiros passos no que tange ao reconhecimento de uma comunidade como remanescente de quilombos. Ver: Paiva e Souza (1999).

${ }^{48}$ Dona Edite, 2012.

${ }^{49}$ Dona Edite, 2012.

${ }^{50}$ Dona Edite, 2009.

${ }^{51}$ Gomes, 2006.

${ }^{52}$ Nora, 1993. 


\section{Referências Bibliográficas}

\section{Bibliografias}

ALBERTI, Verena. Histórias dentro da História. In: PINSKY, Carla Bassanezi (org). Fontes Históricas. São Paulo: Contexto, 2005. p. 155-202.

ANJOS, Rafael Sanzio Araújo dos. Quilombos: Geografia Africana - Cartografia Étnica Territórios Tradicionais. Brasília: Mapas Editora \& Consultoria, 2009.

APOLINÁRIO, Juciene Ricarte. A presença do povo Kariri no sertão da capitania da paraíba entre os séculos XVII E XVIII: primeiros contatos interetnicos, deslocamentos e iniciativas indígenas. Disponível em: <http://www.snh2011.anpuh.org/resources/anais/27/1364957880_ARQUIVO_APRESENCA DOSPOVOSKARIRINOSERTAODACAPITANIADAPARAIBA.pdf > . Acesso: dez. 2013.

ARENDT, Hannah. Entre o passado e o futuro. Tradução de Mauro W. Barbosa. 6. ed. São Paulo: Perspectiva, 2009.

ARRUTI, José Maurício Paiva Andion. Mocambo: Antropologia e História do processo de formação quilombola. Bauru: EDUSC, 2006.

BARTH, Fredrik. O guru, o iniciador e outras variações antropológicas. Tradução de Jonh Cunha Comeford. Rio de Janeiro: contra Capa Livraria, 2000.

Temáticas permanentes e emergentes na análise da etnicidade. In: GOVERS, Cora; VERMEULEN, Hans (org.). Antropologia da etnicidade: para além de ethnic groups and boundaries. Tradução de Rogério Puga. Lisboa: Fim de século, 2003. p. 19-44.

BENJAMIM, Walter. Obras escolhidas, v. I: magia e técnica, arte e política. São Paulo: Brasiliense, 1985.

BORGES, Jorge Luis. Ficções. São Paulo: Companhia das Letras, 2007.

BRASIL. Decreto n. 4.887, de 20 de novembro de 2003. Regulamenta o procedimento para identificação, reconhecimento, delimitação, demarcação e titulação das terras ocupadas por remanescentes das comunidades dos quilombos de que trata o art. 68 do Ato das Disposições Constitucionais Transitórias. Disponível em: 〈http://www.planalto.gov.br >. Acesso: 18 mai. 2008.

CAVALCANTI, Josefa Salete B. Caiana - Reduto de um quilombo? Revista Tudo. 20/10/1983.

CHARTIER, Roger. A História Cultural: entre práticas e representações. Lisboa: Difel; Rio de Janeiro: Editora Bertrand Brasil, 1990. 239 p.

A visão do historiador modernista. In: FERREIRA, Marieta de Moraes; AMADO, Janaína (Org.). Usos \& Abusos da História Oral. 8. ed. Rio de Janeiro: Editora FGV, 2006.

CRUIKSHANK, Julie. Tradição oral e história oral: revendo algumas questões. In: AMADO, Janaína; FERREIRA, Marieta de Moraes Ferreira (cord.). Usos \& abusos da história oral. 8. ed. Rio de Janeiro: Editora FGV, 2006. p. 149- 164.

FALCONI. Um quilombo esquecido. Correio das Artes, João Pessoa. 1949.

FERREIRA, Marieta de Moraes; AMADO, Janaína (Org.). Usos \& Abusos da História Oral. 8. ed. Rio de Janeiro: Editora FGV, 2006.

FERREIRA, Roquinaldo. África durante o comércio negreiro. In: SCHWARCZ, Lilia Moritz; GOMES, Flávio dos Santos (Org.). Dicionário da escravidão e Liberdade: 50 textos críticos. São Paulo: Companhia das Letras, 2018. p. 51-56.

FREIRE, José Avelar. Alagoa Grande: aspectos econômicos e fatos da sua história. João Pessoa: Ideia, 1996. 
FOOTE-WHYTE, William. Treinando a observação participante. In: GUIMARÃES, Alba Zaluar (org.). Desvendando Máscaras Sociais. Rio de Janeiro: Francisco Alves. 1980. p.7786.

GAMBARRA, Rafaela. Esforço para manter as tradições. João Pessoa: Jornal A União. 17/03/2013.

GOMES, Flávio dos Santos. "No labirinto dos rios, furos e igarapés": camponeses negros, memória e pós-emancipação na Amazônia, c. XIX-XX", História Unisinos, v. 10, n. 3 (2006), p. 281-292.

HALBWACHS, Maurice. A memória coletiva. São Paulo: Centauro, 2006.

LIMA, Hezrom Vieira Costa. Negro \& Quilombola: a identidade étnica em questão na comunidade remanescente de quilombos de Caiana dos Crioulos - PB. Cadernos de História, Belo Horizonte, v. 17, n. 27, p. 496-520, out. 2016.

LIMA, Luciano Mendonça de; LIMA, Maria Vitória; ROCHA, Solange. A escravidão e o processo de conquista e ocupação do interior da Paraíba. In: SOUZA, Antonio Clarindo Barbosa de; SOUSA, Fabio Gutemberg R. B.História da Paraíba: ensino médio. Campina Grande: EDUFCG, 2007. p. 45 - 58.

LOPES, Nei. Novo dicionário Banto do Brasil. 2. ed. Rio de Janeiro: Pallas, 2012.

LUIZ, Janailson Macêdo. "Arrocha o bumba negada": cotidiano, tradição e memória das cirandeiras de Caiana dos Crioulos. 2010. 69 f. Monografia (Graduação em História) - Centro de Educação, Universidade Estadual da Paraíba, Campina Grande, 2010.

Das ressignificações do passado: As artes da memória e a escrita da história da comunidade remanescente de quilombos Caiana dos Crioulos, Alagoa Grande - PB. Dissertação (Mestrado em História), Universidade Federal de Campina Grande, Campina Grande, PB, 2013.

MATOS, Hebe Maria; RIOS, Ana Lugão. Memórias do cativeiro: família, trabalho e cidadania no pós-abolição. Rio de Janeiro: Civilização Brasileira, 2005.

MATOS, Hebe Maria. Memórias do cativeiro: narrativa e identidade negra no antigo

Sudeste cafeeiro. In: MATOS, Hebe Maria; RIOS, Ana Lugão. Memórias do cativeiro: família, trabalho e cidadania no pós-abolição. Rio de Janeiro: Civilização Brasileira, 2005. p. 35-136.

MOURA, Clóvis. Quilombos: resistência ao escravismo. São Paulo: Ática, 1987.

NORA, Pierre. Entre memória e história: a problemática dos lugares. Projeto História, São Paulo, n. 10, p. 7-28, 1993.

PAIVA, Ricardo de; SOUZA, Vânia R. Fialho de P. e Souza. Relatório de Identificação: Caiana dos Crioulos - Alagoa Grande/PB. Recife: Fundação Cultural Palmares, 2008.

POLLAK, Michael. Memória, esquecimento, silêncio. Estudos históricos, Rio de Janeiro, v. 2, n. 3, p. 3-15, 1989.

RAMOS, L. M. O papel da tradição oral na constituição do patrimônio cultural e na formação de identidades de comunidades quilombolas no Brasil. In: Encontro Nacional de História Oral, 9., 2008, São Leopoldo. In: Anais do IX Encontro Nacional de História Oral. São Leopoldo: Editora Oikos, 2008. p. 1-11.

REIS, João José. GOMES, Flávio dos Santos (org.). Liberdade por um fio: História dos Quilombos no Brasil. São Paulo: Companhia das Letras, 1996. p. 52-59.

RICOEUR, Paul. A memória, a história, o esquecimento. Campinas: Editora da Unicamp, 2007.

SANTANA, Jussara Manuela Santos de. Territorialidade Quilombola: um olhar sobre o papel feminino em Caiana dos Crioulos, Alagoa Grande, PB. 2011. 95 f. Dissertação (Mestrado em Geografia) - Universidade Federal da Paraíba, João Pessoa, 2011. 
SEEGER, Anthony. Pesquisa de campo: uma criança no mundo. In: Os Índios e nós: estudo sobre sociedades tribais brasileiras. Rio de Janeiro: Campus, 1980. p. 25-40.

\section{Fontes orais}

DONA EDITE. Edite José da Silva. Fonte oral: 4 depoimentos. Jul. 2009. Entrevistador: Janailson Macêdo Luiz, Alagoa Grande.

. Edite José da Silva. Fonte oral: $5^{\circ}$ depoimento. Fev. 2012. Entrevistador: Janailson Macêdo Luiz, Alagoa Grande.

ELZA. ELZA. Elza Ursulino do Nascimento: depoimento. Fev. 2012. Entrevistador: Janailson Macêdo Luiz. Campina Grande: UEPB, 2009. 1 CD.

LUZIA. Maria do Nascimento Oliveira. Fonte oral: $1^{\circ}$ depoimento. Jul. 2009. Entrevistador: Janailson Macêdo Luiz, Alagoa Grande.

. Maria do Nascimento Oliveira. Fonte oral: 2 depoimentos. Fev. 2012. Entrevistador: Janailson Macêdo Luiz, Alagoa Grande.

MANÉ GUILHERME. Manuel Guilherme Xavier. $1^{\circ}$ e 2. ${ }^{\circ}$ depoimentos. Fev. 2012. Entrevistador: Janailson Macêdo Luiz, Alagoa Grande.

MANEL. Manuel Firmino Luiz. $1^{\circ}$ depoimento. Mar. 2012. Entrevistador: Janailson Macêdo Luiz, Alagoa Grande.

ZÉ DUCA. José da Silva. $1^{\circ}$ depoimento. Fev. 2012. Entrevistador: Janailson Macêdo Luiz. Alagoa Grande. 